\title{
Efeito da velocidade de soldagem e anisotropia no cálculo de tensões residuais em chapas soldadas pelo processo GMAW
}

Title: Effect of welding speed and anisotropy in the calculation of residual stresses in welded plates by GMAW welding process

Catarina Esposito Mendes

Escola Politécnica de Pernambuco

Universidade de Pernambuco

50.720-001 - Recife, Brasil

catarina.em12@gmail.com

\author{
Francisco Ilo Bezerra Cardoso \\ Escola Politécnica de Pernambuco \\ Universidade de Pernambuco \\ 50.720-001 - Recife, Brasil \\ ilo@poli.br
}

\author{
Ricardo Artur Sanguinetti \\ Departamento de Engenharia Mecânica \\ Universidade Federal de Pernambuco \\ 50.740-560 - Recife, Brasil \\ ras@ufpe.br
}

\begin{abstract}
Resumo Esse trabalho busca estudar os efeitos da mudança da velocidade de soldagem e efeito da aniso-tropia no cálculo de tensões residuais calculadas pelo método de deslocamento de pontos coordenados (DPC) de chapas laminadas soldadas pelo processo de soldagem GMAW. O material utilizado foi um aço estrutural naval ASTM A131 Grau AH-36, soldado no sentido da laminação e transversalmente a ela com duas velocidades de soldagem, 3,5 e 5,4mm/s. Para analisar o efeito da velocidade de soldagem e a mudança do sentido da laminação em relação ao cordão de solda na tensão residual, e se existe interação entre essas duas condições na resposta da tensão residual foram realizados os testes de hipóteses e do ANOVA, onde encontramos uma forte interação da mudança de velocidade de soldagem na tensão residual e uma influência da combinação da velocidade de soldagem com o sentido de laminação na resposta da tensão residual.
\end{abstract}

Palavras-Chave: tensões residuais, soldagem GMAW, método DPC.

\begin{abstract}
This work intends study the effects of the welding speed changes and the anisotropy effect in the calculation of residual stresses using the method of displacement coordinate points (DCP) of laminated plates welded by GMAW process. The used material was a naval structure steel ASTM A131 grade AH-36, welded by GMAW process, both by rolling direction and transverse to it with two welding speeds, 3.5 and $5.4 \mathrm{~mm} / \mathrm{s}$. To analyze the effect of welding speed and the direction of rolling on the residual stress, and if there is interaction between these two conditions in the response were made the hypothesis testing and ANOVA. Which has found a strong interaction in the residual stress due to the change of welding speed and an influence of the welding speed with the laminating direction in the residual stress response.
\end{abstract}

Keywords: residual stress, DCP method, ANOVA, hypothesis testing. 


\section{Introdução}

Tensões residuais são definidas como as tensões internas que permanecem no material, elemento mecânico ou produto final ao se encerrarem os esforços mecânicos e/ou térmicos. As tensões residuais podem ser prejudiciais para o desempenho de um material ou a vida de um componente mecânico, então é de fundamental importância o conhecimento de suas características e medidas para a prevenção e o controle [1].

As tensões residuais podem existir em peças ou materiais submetidos a diferentes processos térmicos e mecânicos. Nesse trabalho observaremos o comportamento de chapas navais laminadas submetidas ao processo de soldagem.

O objetivo principal desse trabalho é estudar a influência da mudança de velocidade de soldagem e o efeito da anisotropia no cálculo de tensões residuais calculadas pelo método de deslocamento de pontos coordenados (DPC) de chapas laminadas soldadas pelo processo de soldagem GMAW.

Para chegarmos a uma conclusão sobre a influência da velocidade de soldagem e da mudança do sentido da laminação em relação ao cordão de solda na tensão residual, e se existe interação entre essas duas condições, vamos trabalhar com o teste de hipóteses e o ANOVA.

\subsection{Processo de soldagem GMAW}

Soldagem GMAW (Gas Metal Arc Welding) ou MIG/MAG é um método no qual a fonte de calor requerido para fundir o metal é gerada por um arco elétrico formado pela corrente elétrica passando entre o arame nu consumível (alimentado continuamente) e a peça de trabalho. A proteção da região a ser soldada é feita por uma atmosfera de gás inerte e/ou ativo. A nomenclatura MIG é um acrograma advindo do inglês, onde representa Metal Inert Gas e MAG representa Metal Active Gas [1].

Esse processo pode ser realizado de forma automática ou semiautomática. Em ambos os casos, a alimentação do arame-eletrodo é feita mecanicamente. $\mathrm{O}$ arame-eletrodo é chamado assim, pois a partir do ponto de contato elétrico até o metal de base, ele passa a ter a função de condutor elétrico.

O enorme calor desenvolvido pela passagem da corrente pelo arame-eletrodo e a chapa consegue fundir a extremidade do arame e as bordas adjacentes das peças de trabalho, criando uma poça de metal fundido. Esta poça está em um estado líquido bem fluido e turbulento. À medida que o cordão de solda é constituído, o fluxo depositado se resfria e solidifica, formando um material duro e vítreo, que protege a solda até seu resfriamento, sendo obrigatória a posterior retirada.
O gás de proteção tem as funções de ser um meio ionizante e de evitar a contaminação do arame-eletrodo, das gotas de metal fundido em transferência, da poça de fusão pelos gases da atmosfera, conferindo as propriedades de estabilidade do arco e controlando a transferência metálica, consumo do arame-eletrodo e fusão do metal de base [1].

A energia de soldagem, calculada a partir da eficiência do processo de soldagem, da corrente, da tensão e da velocidade de soldagem. A energia de soldagem representa a quantidade de calor adicionada a um material por unidade de comprimento linear, expressa em $\mathrm{kJ} / \mathrm{mm}$, $\mathrm{kJ} / \mathrm{cm}$ ou J/mm. A energia de soldagem (ou aporte térmico) é calculada pela equação (1) [1]:

$$
E=\frac{\eta \times \mathrm{V} \times \mathrm{I}}{v}
$$

Onde:

$\eta$ - eficiência de transferência, a depender do processo;

$\mathrm{V}$ - tensão em volts $(\mathrm{V})$;

I - corrente elétrica em amperes (A);

$\mathrm{v}$ - velocidade linear de soldagem, em $\mathrm{mm} / \mathrm{s}$.

O fluxo de calor durante a soldagem afeta as transformações de fase, modificando, assim, a microestrutura, o ciclo térmico e as propriedades resultantes na área afetada pelo processo. Consequentemente, é esse o grande responsável pela existência das tensões residuais e distorções.

\subsection{Tensões residuais devido ao processo de laminação}

No processo de laminação, as tensões residuais são introduzidas pelas deformações plásticas não uniformes causadas pelos esforços de compressão dos rolos sobre a chapa. Para as chapas consideradas grossas, os grãos da superfície da chapa são deformados e tendem a se alongar, enquanto que os grãos do centro da chapa permanecem sem serem afetados. As fibras da parte central tendem a impedir as fibras superficiais de se alongarem, enquanto as fibras superficiais esticam as da parte central da chapa. Essa diferença no comportamento das fibras resulta em uma distribuição de tensões residuais na chapa, que consiste em elevadas tensões compressivas na superfície e tensões trativas no centro, mostrada na Figura 1 [2]. 


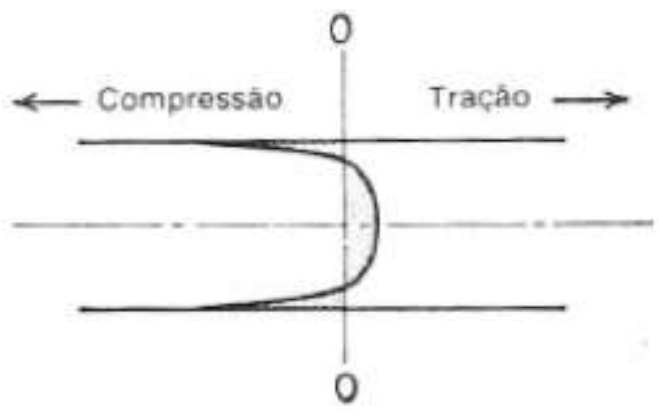

Figura 1: Representação esquemática da distribuição resultante da tensão residual longitudinal ao longo da espessura de chapa $[2]$.

Quando a chapa laminada apresenta deformação homogênea, as fibras superficiais que foram alongadas na direção longitudinal pela laminação permanecem em um estado de tensões residuais compressivas ao se remover a carga externa de laminação.

Para este caso de tensões residuais longitudinais apresentado na Figura 1, a área sob a curva para as tensões residuais compressivas deve se equilibrar com a área sob a curva para as tensões residuais trativas, assim tornando a força total e o momento total em qualquer plano nulo. Entretanto, é importante apontar que a situação real se torna complexa devido à presença de um estado de tensões residuais tridimensional.

\subsection{Tensões residuais devido ao processo de soldagem}

As tensões residuais pelo processo de resfriamento, ocorrem porque as regiões aquecidas e resfriadas são vizinhas. Essa diferença de temperatura fará com que o material dilate e resfrie de forma diferente dependendo da temperatura que cada região vá atingir, de modo que a região do cordão de solda e a sua vizinhança apresentarão tensões térmicas diferentes. Porém, no processo de soldagem de chapas, se existir algum tipo de restrição ao movimento de contração e dilatação, como por exemplo, ponteamento da chapa, surgirão as tensões térmicas residuais à temperatura ambiente. Para o cordão de solda, o acúmulo de tensões térmicas será do tipo tração, atingindo valores da ordem do limite de escoamento do material da solda.

As tensões residuais devido ao resfriamento superficial intenso acontecem ao longo da espessura da junta soldada, já que a parte exposta ao ar ambiente resfria mais rápido que a parte interna. Quando o processo de resfriamento começa, a superfície se contrai rapidamente em relação ao interior da peça, provocando assim o escoamento localizado do material que por sua vez, provocará a existência da tensão residual. Observa-se que as tensões são mais intensas na soldagem de chapas ou tubulações com grandes espessuras. [3].

\subsection{Método de deslocamento de pontos coor- denados para cálculo de tensões residuais}

O método DCP foi desenvolvido por Siqueira Filho em 2012 como um método teórico-experimental alternativo ao método do furo cego. O DCP mede as tensões residuais utilizando uma Máquina de Medição por Coordenadas [4].

O método consiste em realizar pequenos furos com broca de centro de $2,5 \mathrm{~mm}$ de diâmetro por $2 \mathrm{~mm}$ de profundidade e, em seguida cada coordenada $(\mathrm{x}, \mathrm{y})$ do centro dos furos deve ser mapeada na Máquina de Medição por Coordenadas (MMC) com controle numérico computadorizado. Para o mapeamento dos pontos é preciso realizar um ponto de referência em cada chapa. Após essa etapa o material deve ser submetido a um tratamento térmico para o alívio de tensões com temperatura inferior à de recristalização do material. Ao término do tratamento térmico do material os pontos mapeados sofrerão deslocamentos devido ao escoamento do material. Então, os pontos deverão ser novamente mapeados. E a técnica DPC poderá ser aplicada, possibilitando a cálculo das deformações através das equações (2) e (3) para o sentido longitudinal e transversal, respectivamente:

$$
\begin{gathered}
\varepsilon_{x}=\frac{X_{f}-X_{i}}{X_{i}} \\
\varepsilon_{y}=\frac{Y_{f}-Y_{i}}{Y_{i}}
\end{gathered}
$$

Onde:

$\varepsilon x$ : deformação específica na direção $\mathrm{x}$;

$\varepsilon y:$ deformação específica na direção y;

$\mathrm{Xi}$ : Coordenada inicial do ponto na direção x (mm);

Xf: Coordenada final do ponto na direção x (mm);

Yi: Coordenada inicial do ponto na direção y ( $\mathrm{mm})$;

Yf: Coordenada final do ponto na direção y $(\mathrm{mm})$.

Com os valores das deformações específicas nas duas direções, as tensões residuais no estado plano de tensões geradas pelo processo de soldagem podem ser calculadas pelas equações (4) e (5) [6]:

$$
\begin{aligned}
& \sigma_{x}=\frac{E}{1-v^{2}}\left(\varepsilon_{x}+v \varepsilon_{y}\right) \\
& \sigma_{y}=\frac{E}{1-v^{2}}\left(\varepsilon_{y}+v \varepsilon_{x}\right)
\end{aligned}
$$

Onde: 
$\sigma x$ : tensão residual transversal - direção normal à linha de solda (MPa); $(\mathrm{MPa})$

$\sigma y:$ tensão residual longitudinal - direção da solda

عx: deformação específica normal a linha de solda;

عy: deformação específica na linha de solda;

E: módulo de elasticidade do material (GPa);

$v$ : coeficiente de Poisson.

Segundo Okumura [6] os valores das tensões residuais $\sigma x$ e $\sigma y$ são obtidos pela medição de $\varepsilon x$ e $\varepsilon y$, que são os valores das deformações residuais nos pontos onde se deseja conhecer as tensões residuais.

\subsection{Anisotropia}

O material pode apresentar anisotropia cristalográfica, onde existe orientações preferenciais dos grãos, devido ao processo de deformação plástica no material. Esse tipo de anisotropia é mais frequente em metais não-ferrosos, quando são conformados na forma de chapas finas. A tensão de escoamento e a resistência mecânica são as propriedades mais afetadas. $\mathrm{O}$ segundo tipo é chamado de fibramento mecânico e é causado devido ao alinhamento preferencial de descontinuidades estruturais como inclusões, vazios, segregações e outras fases na direção de trabalho da deformação plástica. Este tipo de anisotropia é importante em peças forjadas ou placas grossas. Portanto, a anisotropia está associada com a variação do espaçamento atômico ou iónico e/ou a direção cristalográfica [7].

O efeito Bauschinger [8], está ligado a anisotropia, onde se realizou um ciclo de carregamento mecânico, em um corpo de prova submetido a um esforço de tração até o regime plástico, depois descarregado e, em seguida, recarregado no sentido de compressão, mostrando que o limite de escoamento à tração é diferente do limite à compressão. A Figura 2 apresenta um gráfico de tensãodeformação, onde o efeito Bauschinger é aplicado.

O corpo de prova é submetido a um esforço de tração até a região do regime plástico e atinge o ponto $\mathrm{D}$, sendo então, descarregado, permanecendo uma deformação plástica (ponto G). Em seguida, aplica-se um esforço compressivo até atingir o ponto $\mathrm{D}^{\prime}$. Na Figura 2, os valores em módulo para o limite de escoamento à tração e compressão não coincidem [2]. Esta dependência do sentido do carregamento e o comportamento assimétrico das tensões é conhecida como o efeito Bauschinger.

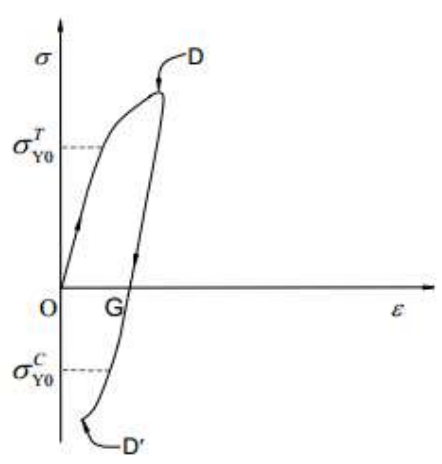

Figura 2: Ciclo de carregamento do Efeito de Bauschinger [8].

Abel e Ham [9] analisaram o efeito Bauschinger através da tensão de recuo. Eles mostraram que a tensão produzida pela deformação no sentido inicial pode ser observada apenas em termos das contribuições dos componentes direcionais e não direcionais de endurecimento. Assumindo que os componentes direcionais da tensão interna não são muito aliviados nas operações de descarga, a tensão de recuo apresenta uma perda de elasticidade. Essa perda entre o valor da tensão de escoamento em uma direção e o valor da tensão de escoamento em outra direção é designado como tensão de recuo.

\subsection{Análise da variância com dois fatores}

Para utilizarmos a análise da variância ou ANOVA, primeiramente precisamos realizar um experimento planejado. O experimento planejado é um teste, ou uma série de testes, no qual são feitas mudanças propositais nas variáveis de entrada de um processo, de modo que podermos observar e identificar mudanças correspondentes na resposta de saída [10].

O objetivo do experimento é determinar quais variáveis são mais influentes na resposta, os seus valores, se existe ou não efeito de combinação dessas variáveis e se esse efeito é significativo ou não.

A ANOVA de dois fatores trabalha com a influência desses fatores na variável dependente, seja de forma isolada ou conjuntamente.

Quando os fatores, por exemplo, A e B exercem uma influência na variável dependente de forma isolada são chamados efeitos principais, e de forma combinada são chamados de combinação específica dos fatores A e B. Cada fator pode apresentar um número de níveis diferentes ou iguais e os ensaios podem ser com o sem repetição.

Os planejamentos fatoriais de dois níveis são utilizados em investigações preliminares, quando deseja-se saber se fatores têm ou não influência sobre a resposta, mas ainda não descreve rigorosamente essa possível influência [11].

O teste de hipóteses analisa uma hipótese estatística 
com base nos elementos amostrais. Onde a $\mathrm{H}_{0}$ (hipótese nula) será testada estatisticamente e o $\mathrm{H}_{1}$ (hipótese não nula) supõe o que o pesquisador quer estudar. Quando se rejeita $\mathrm{H}_{0}$, com nível de significância de $5 \%$, por exemplo, o pesquisador automaticamente aceita sua hipótese não nula [11].

\section{Materiais e métodos}

\subsection{Metal de base}

As chapas utilizadas no trabalho foram fornecidas pelo Estaleiro Atlântico Sul, localizado no Porto de Suape Cabo de Santo Agostinho - PE, com as dimensões de 1200 x 500 x 13,7 mm e classificação ASTM A131 grau AH-36.

Para as chapas de teste serem soldadas foi necessária a preparação das mesmas, sendo preciso cortá-las nas dimensões de 70 × 200 × 13,7 mm com o sentido de laminação transversal e longitudinal, para que os cordões de solda fossem produzidos transversalmente e paralelamente à direção de laminação.

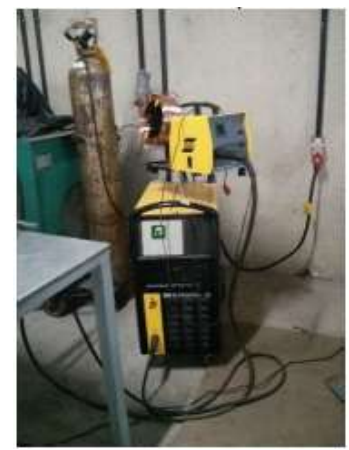

(a)

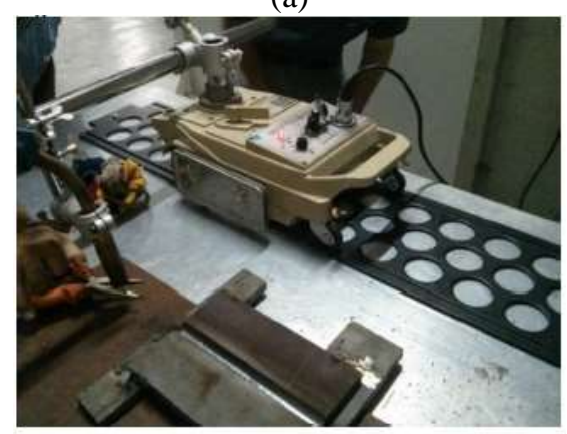

(b)

Figura 3: a) Fonte GMAW para soldagem da ESAB Smashweld 318 Topflex e b) tartaruga utilizada para a soldagem. (Catarina, 2015).

\begin{tabular}{|c|c|c|c|c|c|}
\hline CHAPA & $\begin{array}{l}\text { SENTIDO DA } \\
\text { LAMIINACAAO }\end{array}$ & $\begin{array}{l}\text { TENSAO } \\
\text { MEDIA (V) }\end{array}$ & $\begin{array}{l}\text { CORRENTE } \\
\text { MEDLA (A) }\end{array}$ & $\begin{array}{c}\text { VELOCIDADE } \\
\text { DE } \\
\text { SOLDAGEM } \\
(\mathrm{mm} / \mathrm{s})\end{array}$ & $\begin{array}{c}\text { APORTE } \\
\text { TERMICO } \\
(\mathbf{k J} / \mathrm{m})\end{array}$ \\
\hline 1 & Longitudinal & 19,3 & 220 & 3,5 & 979,1 \\
\hline 2 & Longitudinal & 19,7 & 199 & 3,5 & 914,3 \\
\hline 3 & Transversal & 18,9 & 213,3 & 3,5 & 896,5 \\
\hline 4 & Transversal & 19 & 212,7 & 3,5 & 611,9 \\
\hline 5 & Longitudinal & 18,8 & 219,7 & 5,4 & 572,8 \\
\hline 6 & Longitudinal & 18,1 & 213,6 & 5,4 & 554,5 \\
\hline 7 & Transtersal & 18,1 & 206,8 & 5,4 & 554,7 \\
\hline 8 & Transversal & 18 & 208 & 5,4 & 971,7 \\
\hline
\end{tabular}

Tabela 1: Parâmetros de soldagem utilizados e aporte térmico para cada chapa. (Catarina, 2015)

\subsection{Equipamentos, processo e parâmetros de soldagem}

O processo de soldagem GMAW foi executado de forma semiautomática com uma fonte, Figura 3(a) de soldagem ESAB Smashweld 318 Topflex e uma tartaruga Figura 3(b) fornecidos pelo programa PRH PB203.

Para o processo de soldagem GMAW foi utilizado um arame de bitola de $1,2 \mathrm{~mm}$ e tipo ASME SFA 5.18 ER70S-6, com um gás de $75 \%$ de $\mathrm{Ar}$ e $25 \%$ de $\mathrm{CO}_{2}$.

$\mathrm{O}$ procedimento de soldagem foi executado em chapas com junta de topo, com chanfro de $50^{\circ}$, chanfro tipo $\mathrm{V}$ com nariz de $2 \mathrm{~mm}$ e posição de soldagem $1 \mathrm{G}$. A usinagem dos chanfros foi realizada em um centro de usina- gem do Departamento de Engenharia Mecânica da Universidade Federal de Pernambuco.

As chapas foram soldadas no galpão do Departamento de Engenharia Mecânica da Universidade Federal de Pernambuco. Após cada passe a camada vítrea no cordão de soldagem foi removida com uma escova de aço.

\subsection{Ensaio pelo método de deslocamento de pontos coordenados}

Depois das chapas soldadas, foram realizados furos com brocas de centro de $2,5 \mathrm{~mm}$ de diâmetro por $2 \mathrm{~mm}$ de profundidade sobre a ZTA. Em seguida, as coordenadas $(\mathrm{x}, \mathrm{y})$ do centro de cada furo foram mapeadas em uma Máquina de Medição por Coordenadas (MMC) com controle numérico computadorizado, modelo CRYSTA 
574 (curso de medição de $700 \mathrm{~mm}$ e resolução de 0,0005 $\mathrm{mm}$ ), fabricação MITUTOYO, ano 2004, com certificado de calibração 03206/2013, do Laboratório de Medição por Coordenada (LAMECO) do Departamento de Engenharia Mecânica da Universidade Federal de Pernambuco - UFPE.

Após a realização do mapeamento inicial dos pontos em cada chapa, foi preciso realizar um tratamento térmico de alívio de tensão à temperatura de $680{ }^{\circ} \mathrm{C}$ por 30 min. Ao término do TT do material, os pontos mapeados sofreram deslocamentos devido ao escoamento do mate- rial e com isso, foram novamente mapeados. Destas novas coordenadas dos centros dos furos medidas na MMC, foram encontradas as deformações geradas pelo processo de soldagem.

Com os valores das coordenadas de antes e depois do tratamento térmico de cada furo, foram calculadas as deformações pelas equações 2 e 3 e posteriormente, as tensões residuais pelas equações 4 e 5 em cada ponto.

A Tabela 2 demonstra os deslocamentos dos pontos coordenados medidos na máquina de medição por coordenadas.

\begin{tabular}{|c|c|c|c|c|c|c|c|c|}
\hline \multirow{2}{*}{$\begin{array}{c}\begin{array}{c}\text { Velocidade } \\
\text { de soldagem } \\
(\mathrm{mm} / \mathrm{s})\end{array} \\
3.5\end{array}$} & \multirow{2}{*}{$\begin{array}{l}\text { Sentido de } \\
\text { laminação }\end{array}$} & \multicolumn{6}{|c|}{ Deslocamento em X (mm) } & \multirow{2}{*}{$\begin{array}{c}\begin{array}{c}\text { Média } \\
\text { para X } \\
(\mathbf{m m})\end{array} \\
0,005\end{array}$} \\
\hline & & 0,010 & 0,001 & 0,006 & 0,007 & 0,006 & 0,001 & \\
\hline 5,4 & Longitudinal & 0,014 & 0,014 & 0,013 & 0,036 & 0,035 & 0,081 & 0,032 \\
\hline 3,5 & Transversal & 0,011 & 0,010 & 0,006 & 0,003 & 0,003 & 0,004 & 0,006 \\
\hline 5,4 & Transversal & 0,003 & 0,003 & 0,002 & 0,016 & 0,004 & 0,006 & 0,006 \\
\hline $\begin{array}{c}\text { Velocidade } \\
\text { de soldagem } \\
(\mathrm{mm} / \mathrm{s})\end{array}$ & $\begin{array}{l}\text { Sentido de } \\
\text { laminação }\end{array}$ & \multicolumn{6}{|c|}{ Deslocamento em Y (mm) } & $\begin{array}{c}\text { Média } \\
\text { para Y } \\
\text { (mm) }\end{array}$ \\
\hline 3,5 & Longitudinal & 0,013 & 0,001 & 0,012 & 0,011 & 0,010 & 0,013 & 0,010 \\
\hline 5,4 & Longitudinal & 0,024 & 0,028 & 0,031 & 0,055 & 0,047 & 0,089 & 0,046 \\
\hline 3,5 & Transversal & 0,017 & 0,019 & 0,014 & 0,005 & 0,006 & 0,006 & 0,011 \\
\hline 5,4 & Transversal & 0,005 & 0,005 & 0,004 & 0,026 & 0,008 & 0,015 & 0,011 \\
\hline
\end{tabular}

Tabela 2: Deslocamentos dos pontos coordenados medidos através da máquina de medição por coordenadas. (Catarina. 2015).

Para todas as combinações de parâmetros $(\mathrm{A}, \mathrm{B})$ os valores dos deslocamentos dos pontos na direção y são preferencialmente maiores (direção do cordão de solda). Porém, quando trabalhamos com os cordões de soldados no sentido transversal, os deslocamentos tendem a assumir valores mais próximos.

Essa condição acontece, pois, durante o TT a tensão de recuo atua revertendo as barreiras (discordâncias bloqueadas) contribuindo para o deslocamento (escoamento) na direção contrária à plastificação. Entretanto, com a soldagem no sentido transversal a laminação, a tensão de recuo não atua revertendo as barreiras, pois o escoamento é na direção da plastificação.

A Tabela 3 demonstra os resultados das medições de tensões residuais em $\mathrm{X}$ e $\mathrm{Y}$ pelo método DPC. Onde pode-se observar que a maior média das tensões residuais foram para a maior velocidade de soldagem (aporte térmico menor) concordando com o trabalho de Peel et al. [12], onde foi observado que o aumento do aporte térmico através da redução da velocidade de soldagem resulta na redução da tensão residual.

\begin{tabular}{|c|c|c|c|c|c|c|c|c|}
\hline \multirow{2}{*}{$\begin{array}{c}\begin{array}{c}\text { Velocidade } \\
\text { de soldagem } \\
(\mathrm{mm} / \mathrm{s})\end{array} \\
3,5\end{array}$} & \multirow{2}{*}{$\begin{array}{l}\text { Sentido de } \\
\text { laminação }\end{array}$} & \multicolumn{6}{|c|}{ Tensão residual em X (MIPa) } & \multirow{2}{*}{$\begin{array}{c}\begin{array}{c}\text { Media } \\
\text { para X } \\
\text { (AIPa) }\end{array} \\
44,4\end{array}$} \\
\hline & & 81,6 & 5,0 & 55,7 & 61,1 & 56,9 & 6,1 & \\
\hline 5,4 & Longitudinal & 124,9 & 129,8 & 128,5 & 162,9 & 143,6 & 117,4 & 134,5 \\
\hline 3,5 & Transversal & 97,3 & 92,5 & 60,7 & 25,3 & 30,1 & 37,1 & 57,2 \\
\hline 5,4 & Transversal & 26,9 & 24,8 & 18,6 & 138,2 & 37,2 & 62,8 & 51,4 \\
\hline $\begin{array}{l}\text { Velocidade } \\
\text { de soldagem } \\
(\mathrm{mm} / \mathrm{s})\end{array}$ & $\begin{array}{l}\text { Sentido de } \\
\text { laminação }\end{array}$ & \multicolumn{6}{|c|}{ Tensão residual em Y (MPa) } & $\begin{array}{l}\text { Média } \\
\text { para Y } \\
\text { (MIPa) }\end{array}$ \\
\hline 3,5 & Longitudinal & 79,7 & 5,4 & 65,7 & 64 & 65,9 & 7,7 & 48,1 \\
\hline 5,4 & Longitudinal & 135,7 & 154,4 & 165,3 & 163,5 & 154,6 & 222,7 & 166,0 \\
\hline 3,5 & Transversal & 99,6 & 104,7 & 74,8 & 26,6 & 34,5 & 36,1 & 62,7 \\
\hline 5,4 & Transversal & 28,0 & 28,8 & 23,9 & 148,8 & 44,1 & 82,6 & 59,4 \\
\hline
\end{tabular}

Tabela 3: Resultados das tensões residuais calculadas através da Lei de Hooke. (Catarina, 2015). 


\subsection{Resultados do planejamento fatorial e do ANOVA}

Os testes de hipóteses para o fator A, a velocidade de soldagem e o fator B, o sentido de laminação, portanto, as hipóteses nulas são:

H0: Não há efeito principal da velocidade de soldagem;

H0: Não há efeito principal do sentido de laminação;

H0: Não há combinação de efeitos;

E a hipótese não nula é:

H1: Há efeito em cada um dos três casos.

A Tabela 4 mostra os valores de P-valor para os efeitos dos fatores individualmente e do efeito de interação tanto para tensões residuais em $\mathrm{X}$ quanto para $\mathrm{Y}$.

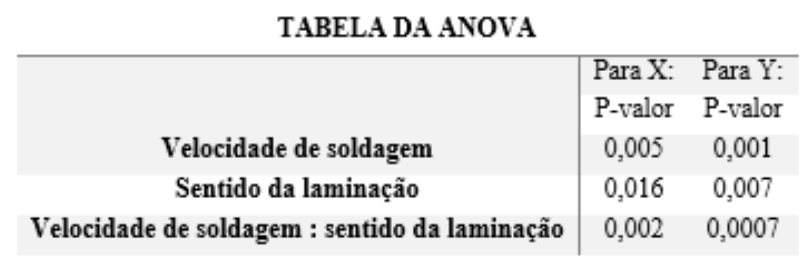

Tabela 4: Valores de p-valor para o teste de hipóteses. (Action Stat)

As hipóteses nulas são rejeitadas quando comparamos os valores de $\mathrm{P}$ calculados com o P-valor de 0,05 [13]. Ou seja, temos $95 \%$ de certeza que as hipóteses nulas são falsas, então, há efeito da velocidade de soldagem e do sentido de laminação na tensão residual ,e, também há uma combinação desses dois efeitos na resposta. Portanto, podemos observar esses efeitos através dos gráficos de efeitos e interações.

Para observar os efeitos principais e de interações dos efeitos um planejamento fatorial $2^{2}$ foi realizado. Os fatores foram a velocidade de soldagem e o sentido de laminação em relação ao cordão de solda e para cada fator foram utilizados dois níveis. Para a velocidade de soldagem foi escolhido duas velocidades de $3,5 \mathrm{~mm} / \mathrm{s}$ (V0) e $5,4 \mathrm{~mm} / \mathrm{s}$ (V1), e para o sentido da laminação também foram escolhidos o sentido longitudinal (L0) e transversal (L1) à laminação do cordão de solda. Para cada combinação de fatores e níveis foram trabalhados 6 pontos. Quando o método DPC foi utilizado para medir as tensões residuais, conseguimos montar a nossa matriz de planejamento mostrada na Tabela 3 anteriormente.

Utilizando o software Action Stat versão 3.1.43.694.649 ano 2016 podemos analisar o efeitos da velocidade de soldagem e do sentido de laminação na cálculo das tensões residuais.

Podemos quantificar o valor do efeito principal da velocidade de soldagem, do sentido de laminação e o efeito de interação entre os dois fatores. O efeito principal é a diferença entre a resposta média no nível superior e a resposta média no nível inferior de cada fator, equação 6 :

$$
\text { Fator }=\overline{y_{+}}-\overline{y_{-}}
$$

Onde:

Fator: o fator que você deseja calcular;

$\overline{y_{+}}:$diferença da resposta média no nível superior;

$\overline{y_{-}}$: diferença da resposta média no nível inferior.

Para o efeito de interação utilizamos a diferença entre a média das tensões entre cada fator, equação 7 .

$$
\text { Interação }=\left(\frac{\Delta \text { Tensão } 2-\Delta \text { Tensão } 1}{6}\right)
$$

Onde:

Interação: interação entre os fatores;

$\Delta T e n s \tilde{a} d$ : diferença da resposta média do fator 1 ;

$\Delta T e n s \tilde{a} 2$ : diferença da resposta média do fator 2 .

A Figura 4 demonstra que a tensão residual em $\mathrm{X}$ é mais sensível a mudança da velocidade de soldagem que a mudança do sentido de laminação.

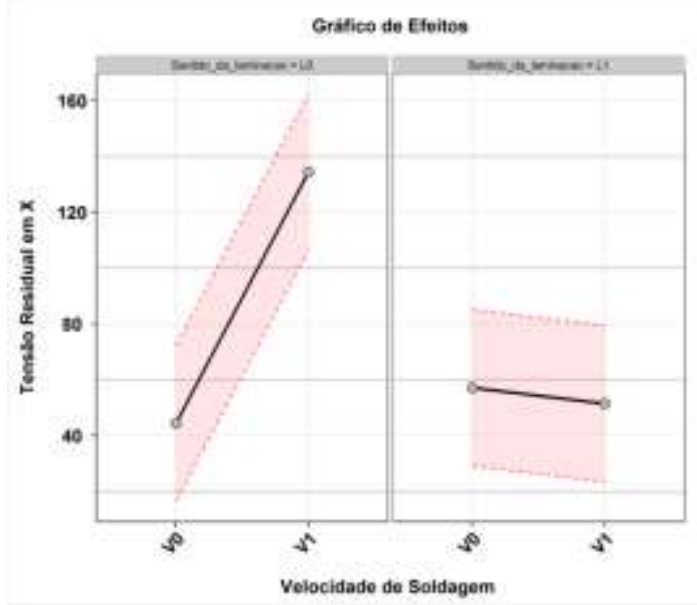

Figura 4: Gráfico de efeitos da velocidade de soldagem e sentido de laminação na tensão residual em X.

Quando aumentamos a velocidade de soldagem de 3,5 $\mathrm{mm} / \mathrm{s}$ para $5,4 \mathrm{~mm} / \mathrm{s}$ a tensão residual média em $\mathrm{X}$ aumenta de 44,4 MPa para 134,5 $\mathrm{MPa}$ resultando em um acréscimo de 90,1 $\mathrm{MPa}$. E quando mudamos o sentido de laminação a tensão residual média em X diminui de 57,2 para 51,4 MPa resultando em uma redução de 5,8 $\mathrm{MPa}$. Isso mostra que o efeito da velocidade de soldagem na tensão residual depende do sentido de laminação e o 
efeito do sentido da laminação na tensão residual depende da velocidade de soldagem.

A Figura 5 demonstra o gráfico de interações dos dois fatores.

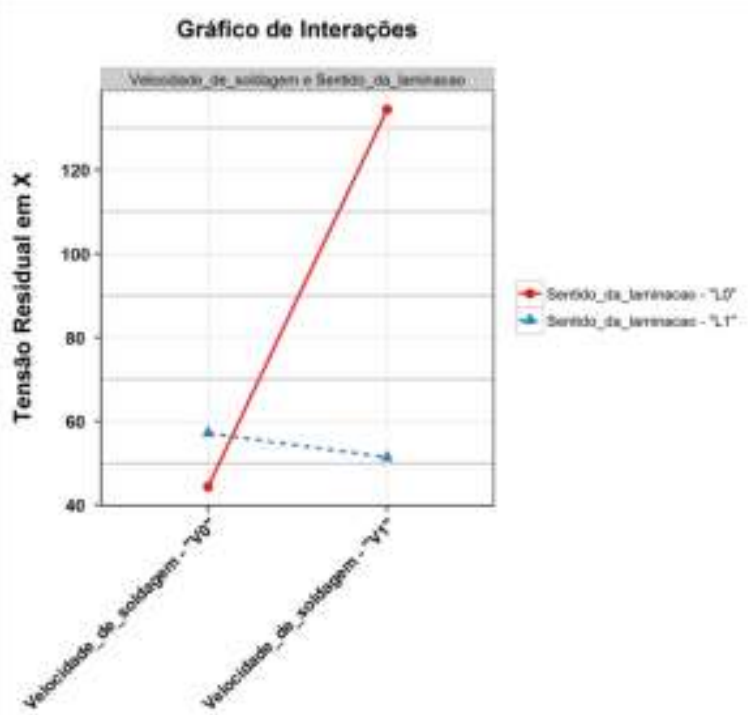

Figura 5: Gráfico de interações entre a velocidade de soldagem e sentido de laminação na tensão residual em X.

Para a velocidade de soldagem o valor do efeito principal é, equação 8:

$$
V x=134,5-51,4=83,1 \cdot M P a
$$

E para o sentido de laminação, equação 9:

$$
L x=44,4-57,2=-12,8 \cdot M P a
$$

Para o efeito de interação utilizamos o valor do efeito V correspondente ao nível inferior da velocidade de soldagem (que é o tipo A, pela nossa convenção de sinais) do valor correspondente ao nível superior (tipo B), equação 10.

$$
V L x=\frac{90,1-(-5,8)}{6}=16 \cdot M P a
$$

A Figura 6 demonstra que a tensão residual em Y também é mais sensível a mudança da velocidade de soldagem que a mudança do sentido de laminação.

Quando aumentamos a velocidade de soldagem de 3,5 para $5,4 \mathrm{~mm} / \mathrm{s}$ a tensão residual média em Y aumenta de $48,1 \mathrm{MPa}$ para $166,0 \mathrm{MPa}$ resultando em um acréscimo de 117,6 MPa. E quando mudamos o sentido de laminação a tensão residual média em $\mathrm{X}$ diminui de $62,7 \mathrm{MPa}$ para 59,4 $\mathrm{MPa}$ resultando em uma redução de 3,3 $\mathrm{MPa}$. Isso mostra que o efeito da velocidade de soldagem na tensão residual depende do sentido de laminação e viceversa.

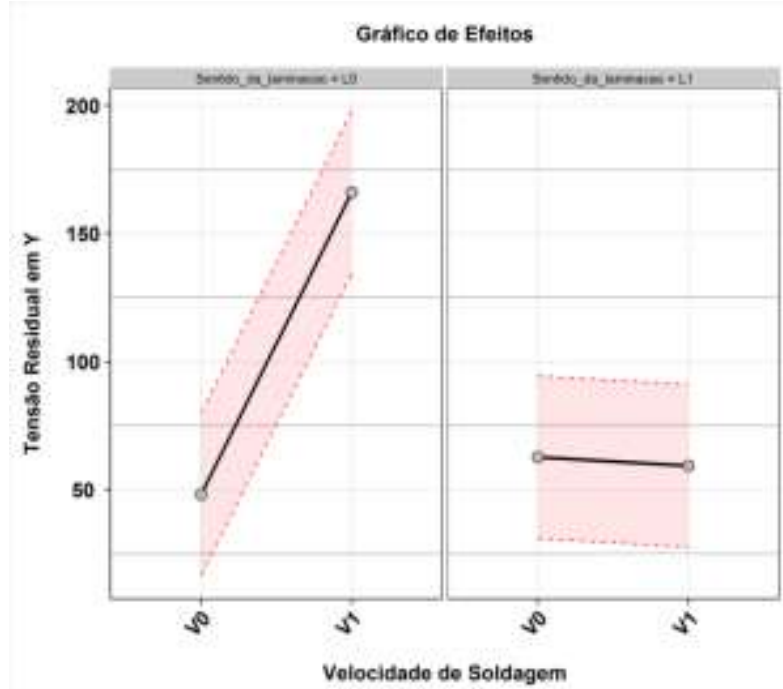

Figura 6: Gráfico de efeitos da velocidade de soldagem e sentido de laminação na tensão residual em Y.

A Figura 7 demonstra o gráfico de interações dos dois fatores.

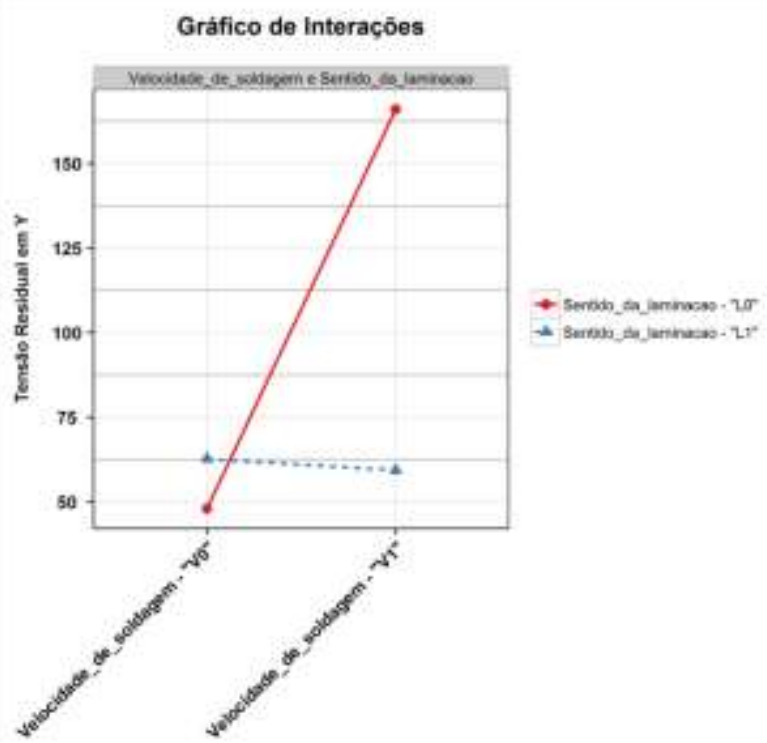

Figura 7: Gráfico de interações entre a velocidade de soldagem e sentido de laminação na tensão residual em Y.

Para a velocidade de soldagem o valor do efeito principal é (equação 11):

$V y=166,0-59,4=106,6 . M P a$

E para o sentido de laminação, equação 12:

$L y=48,1-62,7=-14,6 \cdot M P a$

Para o efeito de interação utilizamos o valor do efeito $\mathrm{V}$ correspondente ao nível inferior da velocidade de soldagem (que é o tipo A, pela nossa convenção de sinais) 
do valor correspondente ao nível superior (tipo B), equação 13:

$$
V L y=\frac{117,6-(-3,3)}{6}=20,1 \cdot M P a
$$

Esses resultados mostram que a tensão residual tanto em X quanto em Y são mais afetadas pela mudança de velocidade de soldagem que pelo sentido da laminação, entretanto, o efeito da interação desses dois fatores é maior que o efeito produzido pela mudança do sentido da laminação.

\section{Conclusões}

Para os parâmetros escolhidos nesse trabalho e os níveis escolhidos, conclui-se que:

Ao diminuirmos a velocidade de soldagem, conseguimos diminuir a tensão residual em até $107 \mathrm{MPa}$.

Ao soldarmos o cordão de solda no sentido transversal a laminação, aumentamos a tensão residual em até 15 $\mathrm{MPa}$. Porém, quando aumentamos a velocidade de soldagem e o sentido de laminação, a tensão residual aumenta em até $20 \mathrm{MPa}$.

Desta forma, deve-se preferir a utilização de velocidade de soldagem menores para tensões residuais menores.

Quando soldamos no sentido da laminação o efeito da tensão residual em Y é ampliado pela tensão de recuo do material..

\section{Referências}

[1] P. V. Marques, P. J. Modenesi, a. Q. Bracarense. Soldagem: Fundamentos e Tecnologia. 3 ed. Editora UFMG, Belo Horizonte, capítulos 7 e 15, 2011.

[2] G. E. Dieter. Mechanical Metallurgy. 3rd ed., Mc Graw-Hill Book Co., New York 1986.

[3] G. L. Oliveira. Avaliação de Tensões Residuais de Soldagem em Chapas Planas do Aço Estrutural ASTM A516 G70. Dissertação de Mestrado. Universidade Federal do Ceará, Fev 2009.

[4] A. V. Siqueira Filho. Estudo Comparativo das Tensões Residuais em Juntas Soldadas pelas Técnicas de Medição por Coordenadas e Difração de Raios-X. Tese de Doutorado. Universidade Federal de Pernambuco, Fev 2012.

[5] T. L. Rolim. Sistemática indicadora de método para calibração de máquinas de medição por coordenadas. Tese de Doutorado. Universidade Federal da Paraíba. Dez 2003.

[6] T. Okumura, C. Tanigusgi. Engenharia de soldagem e aplicações. Livros Técnicos e Científicos Editora, Rio de Janeiro, 1982.

[7] Jr. W. D. Callister. Ciência e engenharia de materiais: uma introdução. Livros Técnicos e Científicos Editora, Rio de Janeiro, 2002.

[8] Dieter, G.E, Mechanical Metallurgy, 2nd ed., McGraw-Hill, Tokyo, 1976.

[9] A. Abel, R. K. Ham. The cyclic strain behaviour of crystals of aluminum- 4 wt. $\%$ copper-i. the bauschinger effect Acta Metalurgical, 14, p $1489,1966$.

[10] D. C. Montgomery, G. C. Runger. Estatistica Aplicada e Probabilidade para Engenheiros. 4 ed. LTC. Rio de Janeiro, 2009.

[11] G. E. P. Box, W.G. Hunter e J.S. Hunter. Statistics for Experimenters: An introduction to design, data analysis, and model building. John Wiley \& Sons. Nova Iorque, 1978.

[12] M. Peel, A. Steuwer, M. Preuss,P. J. Withers. Microstructure, mechanicalproperties and residual stresses as a function of welding speed in aluminium AA5083 friction stir welds. Acta Mater. 51, p 4791-4801, 2013.

[13] S. Vieira. Biostatistica tópicos avançados. Elsevier editora LTD. 3 ed. Rio de Janeiro, 2011. 